\title{
Heat Transfer Characterization of Enhanced Condenser Tubes; Comparison with Conventional Type, Utilizing a Developed Design for Test Apparatus
}

\author{
A. Kalendar, T. Galal*, A. Al-Saftawi, M. Zedan, S. S. Karar and R. El-shiaty \\ Department of Mechanical \& Refrigeration Engineering, College of Technological Studies, PAAET, Kuwait
}

\begin{abstract}
Estimating the feasibility of intensifying thermal mechanisms in MSF plant is investigated by employing Enhanced Tubing Test Apparatus for heat transfer characterization with conventional type. Utilizing actual Brine water, study the influence of flow speeds on fouling pattern and the effect of tube diameter on its behaviour. Experimental results are discussed for both smooth and corrugated tube, when applying fresh and real brine water on different tube diameters 19.05, 23 and 29.5, on flow speeds $0.1,0.1645$ and $0.2398 \mathrm{~m} / \mathrm{s}$. Apparatus (A) has to be redesigned, since problems were developed through its components. Difficulties revealed with former test-rig, are given a careful consideration in assembly of a new one. The modified set-up facilities included a new configured design for the steam condenser, equipped in such a way to minimize mentioned obstacles, dismantling faced problems associated with; circulated pumps, boiler, flow meters and its place of fitting, careful identifying the tested tube characteristics, a wise differentiation between properties of brine and fresh water, a creation of uniform steam temperature distribution inside the rig, preventing a creation of two phase flow and simulating the actual circumstances in real desalination platform. The continuous experimental running hours used by this designed test-rig(B) is $160 \mathrm{hrs}$. Use is made of two horizontally mounted tubes through which the coolant solution is flowing. Corrugated and smooth tubes are examined at a time to unify the tested conditions on both. The study is carried-out for two different coolants, fresh and brine water. Examining effect of fouling on both corrugated and smooth tube, changing tube diameters and coolant flow speeds on experimental data. Results are provided in the form of: overall heat transfer coefficient with fresh and brine water vs. time for both tubes on different flow speeds, overall heat transfer coefficient with brine water vs. time for both tubes on a critical coolant flow speed with various chosen tube diameters, asymptotic values of overall heat transfer coefficient with fresh water vs. tube diameters for both corrugated and smooth on a critical flow speed, asymptotic values of overall heat transfer coefficient with brine water vs. coolant flow speeds for both corrugated and smooth with a chosen critical tube diameter and the tube fouling resistance vs. time, using tube diameter $23 \mathrm{~mm}$ and coolant flow velocity $0.1 \mathrm{~m} / \mathrm{s}$. On global look this study is significant to provide a useful correlation; as the studied tube diameter increased; with increasing flow speed expectation is for achieving a higher value of asymptotic overall heat transfer coefficient.
\end{abstract}

Keywords: Heat Transfer; Smooth tube; corrugated tube; Condenser Tubing; MSF system; Desalination

\section{Introduction}

Brine water use to flow inside the tubes of a condenser, while been heated by the condensing steam on the outside of these tubes [1]. Fouling are formed on the inside surface of the tubes, acting as thermal insulation, decreasing the thermal efficiency of the system. The essence of fouling influences on the performance of the smooth tube condenser is investigated. Enhanced heat transfer technique is been suggested for use to improve tubing heat transfer performance in MSF system. Enhanced heat transfer surface has a special geometry, provides a higher heat transfer coefficient or a wider surface per unit space area's than a traditional design. Heat exchanger of refrigeration and automotive industries are encountered enhanced heat transfer mechanisms in their applications. Such technique can be used with any heat exchanger. However, each must be tested to see if this particular application makes sense. Unfortunately all current MSF systems are designed using smooth surface tubes, mainly because of finding the complexity effects of fouled brine water on available heat transfer mechanisms. Enhanced technique and fouling versus heat exchanger have been of interest for a number of years and for a number of researchers [2-16]. The above mentioned facts have influenced our research direction and thrown lights on the current work. This includes: a) choosing our tube roughened enhancement, b) study the effect of flow speed and tube diameter on performance characteristic of the multi-stage flashing system and c) utilizing actual coolant brine, avoiding the use of artificial fouling will not leads to misleading results. Achieving good results will support current idea of trying enhanced tube surface on a distillation unit with multi-stage flashing system. In other words, the approach of current research programme is itemized to use a research rig that simulates one stage of an MSF desalination heat exchange process. The feasibility of enhanced heat transfer mechanism is assessed using actual brine water that typifies real process conditions. The influence and effect of flow speeds and tube diameter on tube performance and fouling resistance are presented.. Future study is to examine the effect of both tube material and diameter on fouling resistance. Formulation of fouling is by no means an easy task due to the number/types of parameters involved. Enhanced tubes have been discussed in many publications. The analytical treatment of these two subject areas is complicated. However, an experimental study; fouling vs. smooth pipes and fouling vs. enhanced pipes, provides the basic foundation for comprehension, with the prospective formulation of an empirical engineering model to describe its behaviour. Rudy T. M. [17] in his condensate retention test used an ap-

*Corresponding author: Dr. Tarek Galal, 20 Matignan, D.D.O. QC, H9A 2B8, Canada, Email: trgalal70@hotmail.com

Received March 19, 2012; Accepted April 21, 2012; Published April 23, 2012

Citation: Kalendar A, Galal T, Al-Saftawi A, Zedan M, Karar SS, et al. (2012) Heat Transfer Characterization of Enhanced Condenser Tubes; Comparison with Conventional Type, Utilizing a Developed Design for Test Apparatus. J Appl Mech Eng 1:105. doi:10.4172/2168-9873.1000105

Copyright: (c) 2012 Kalendar A, et al. This is an open-access article distributed under the terms of the Creative Commons Attribution License, which permits unrestricted use, distribution, and reproduction in any medium, provided the original author and source are credited. 
Citation: Kalendar A, Galal T, Al-Saftawi A, Zedan M, Karar SS, et al. (2012) Heat Transfer Characterization of Enhanced Condenser Tubes; Comparison with Conventional Type, Utilizing a Developed Design for Test Apparatus. J Appl Mech Eng 1:105. doi:10.4172/21689873.1000105

paratus where condensation occurs inside a horizontal bell-jar that is flanged to a flat brass back-plate. This provides a test cell that can be pressurized. The test sections of integral-fin tube are approximately 51 mm long. Insulated $3.2 \mathrm{~mm}$ copper tubing carries the cooling water through the back-plate to and from the test tube. A pan, positioned under the test tube, collects the condensate to allow calculation of the liquid loading and heat flux. Vapour is generated by a cartridge-heater in the lower portion of the test cell. Thermocouples are inserted to measure the cooling water temperatures in and out. Chamra L. M. [18] in his experimental work used an apparatus which is capable of testing four $19 \mathrm{~mm}$ O.D., or three $22 \mathrm{~mm}$ O.D., tubes simultaneously. The instrumentation includes an on-line data acquisition system driven by a personal computer, which is used to measure thermostat and pressure transducer outputs. The apparatus is designed to operate and record data 24 hour/day. Heat is transferred to the tube long test sections by condensing the coolant on the annulus side of the test section. Condensed coolant is returned to electric heated boilers. Wei Li [19] used an apparatus to study the effect of fouling in enhanced tubes in cooling tower systems. A fouling heat exchanger is connected in parallel with the 250 ton chillers. The fouling test tubes are installed in the heat exchanger. Eight special I.D. enhanced tube geometries are made by Wolverine for the fouling tests.

In this paper the advantages of presented apparatus are; its system capability to work precisely over 160 hour continuously with- out malfunction, use of real brine water instead of artificial fouling, uniform distribution of steam and so its temperature and eliminate the existence of accumulated gases inside the steam drum. The aims of the approach for current research can be itemized as follows: design a research rig that simulates the desalination heat exchange process to study and assess the feasibility of enhanced heat transfer mechanisms in MSF plant, with: examining actual brine water that typifies real process conditions, study the influence and effect of flow speeds as well as tube diameter on fouling resistance [20-24]. Discussion is concerned with the design development of our test-rig (A) to test-rig (B). A comparative analysis for the overall heat transfer coefficient and fouling effects are obtained and discussed on both designs. Reported measurements and results provide in global the methodology as well as parametrical interpretation, where many new proposition, inquiry and problems had been identified. Also, discussion embraced some of these new problems. Revealed suggestions and recommendations by the acquired test-results (A) are given careful consideration in carrying-out the design, calibration and measurements for test-rig (B).

\section{Overall Heat Transfer Coefficient}

Reported equations by reference [1] display expression for overall heat transfer coefficient, function of system properties as follow:

$$
U=\frac{\dot{m} C_{P}}{A} \ln \left[\frac{T_{s}-T_{i}}{T_{s}-T_{o}}\right], \quad \quad \mathrm{kW} / \mathrm{m}^{2}{ }^{\circ} \mathrm{C}
$$

With, $A$ is a nominal inside surface area, with $A=\pi D_{i} L, D_{i}$ is tube inside diameter and $\mathrm{L}$ is a tube Length. $\dot{m}$ is coolant mass flow rate and $C p=4.2 \mathrm{~kJ} / \mathrm{kg}^{\circ} \mathrm{C}$ for fresh water coolant, while $C p$ for brine water is been calculated function of the temperature as given by [20]. $T_{S}$ is saturated vapour temperature. $T_{i}$ and $T_{o}$ are coolant inlet and outlet temperature respectively. Above system properties, $\dot{m}, T_{S}, T_{i}$ and $T_{o}$ are determined by measurement. Consequently, overall heat transfer coefficient $U$ is determined from equation (I). Current experimental data is recorded every half-minute for seven channels during test and these data are averaged and printed out every half-hour for each channel. Figure 1 shows a condenser heat exchanger Tubing.

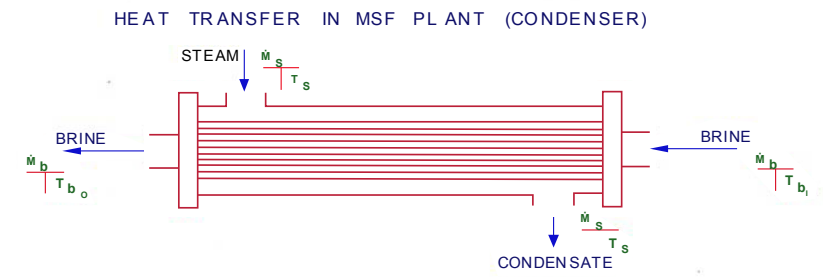

Figure 1: Tubing of a Condenser Heat Exchanger [12]

\begin{tabular}{|c|c|}
\hline Materials & Copper-alloy \\
\hline Sort & Smooth \\
\hline Dimensions & $\begin{array}{r}\text { Inner diameter }\left(\mathrm{D}_{\mathrm{i}}\right)=17.70 \mathrm{~mm} \text {, Outer } \\
\text { diameter }\left(\mathrm{D}_{\mathrm{o}}\right)=22.2 \mathrm{~mm} \\
\text { Tube length }(\mathrm{L})=1.0 \mathrm{~m}\end{array}$ \\
\hline Number of processed tubes & $6 \mathrm{tube}$ \\
\hline $\begin{array}{c}\text { Number of tubes for data correlations } \\
\text { Recorded rate of mass flow " } m_{b} \text { “ } \\
\text { Flow Speed "V" }\end{array}$ & $\begin{array}{c}4 \text { tube (tube no.2,3,4, and 5, excluding } \\
\text { no.1 and 6) }\end{array}$ \\
\hline $\begin{array}{c}\text { Fresh \& Brine water inlet temperature } \\
\text { " } T_{b i}\end{array}$ & $\begin{array}{c}0.522 \mathrm{l} / \mathrm{min} \\
0.035 \mathrm{~m} / \mathrm{sec}\end{array}$ \\
\hline
\end{tabular}

Table 1: Test tube information.

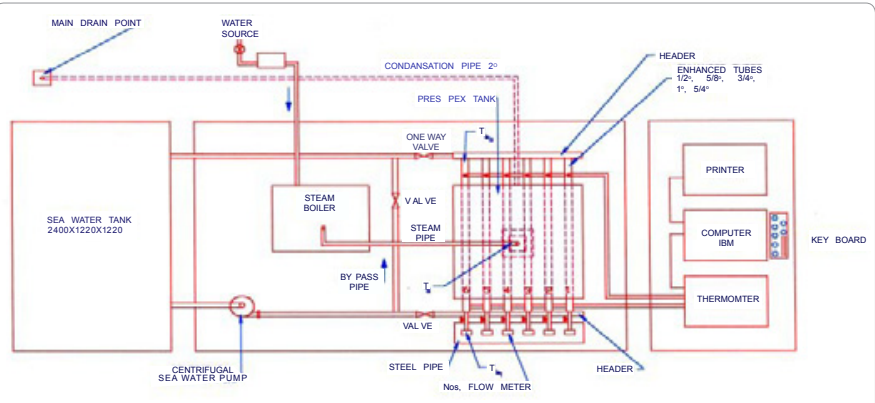

Figure 2a: A Horizontal plan of Experimental Set-up [12]

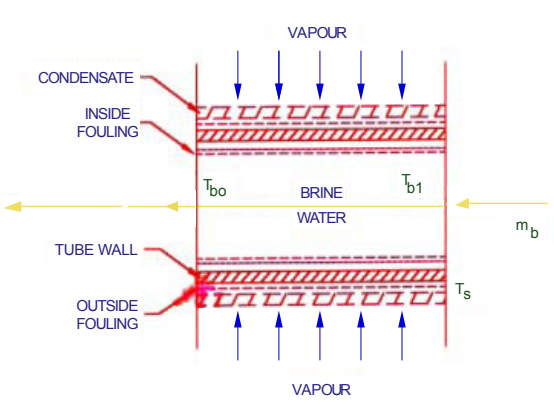

Figure 2b: A Longitudinal section of the tube [12].

\section{Involved Parameters}

The pre-measured parameters recorded during experiment are common for both proceeding test rigs. These are fluid flow rate and its inlet and outlet temperatures. Table 1 highlights the tested tube data (test rig (A)).

\section{Experimental Observations on Test-rig (A)}

A complete lay-out test-rig facility with its axillaries is shown in figure $2 \mathrm{a}$. The apparatus consists mainly of a boiler, where usually the 
Citation: Kalendar A, Galal T, Al-Saftawi A, Zedan M, Karar SS, et al. (2012) Heat Transfer Characterization of Enhanced Condenser Tubes; Comparison with Conventional Type, Utilizing a Developed Design for Test Apparatus. J Appl Mech Eng 1:105. doi:10.4172/21689873.1000105

Page 3 of 8

outlet steam is in a superheated condition, but to reach the rig in a saturation status. Six horizontally mounted tubes through which the coolant solution is flowing and the vapour condenses outside these tubes, but inside a cubic box $(1 m \times 1 m \times 1 m)$ simulating the steam condenser. These tubes are $1 \mathrm{~m}$ long, with a nominal (commercial) inside diameter of $3 / 4$ inch. Figure $2 b$ shows a longitudinal section of the tube.

\section{Plotted data \& results}

Experiment is done to show the temperature variation through each tube the overall heat transfer variation through each with comparing obtained values. The difference exists between fresh water and brine collected data. Finally, is to show the effect of fouling on reducing the value of the overall heat transfer.

When brine water is used, figure 3 shows the variation of $U_{i}$ as a function of time for some chosen tubes. The declining of overall heat transfer coefficient for all tubes, with time, continues until approaching the steady state conditions. While, when potable water is used, system is approaching the quasi-equilibrium state as the time goes-on, with a higher value of $U_{i}$ as shown in figure 4 .

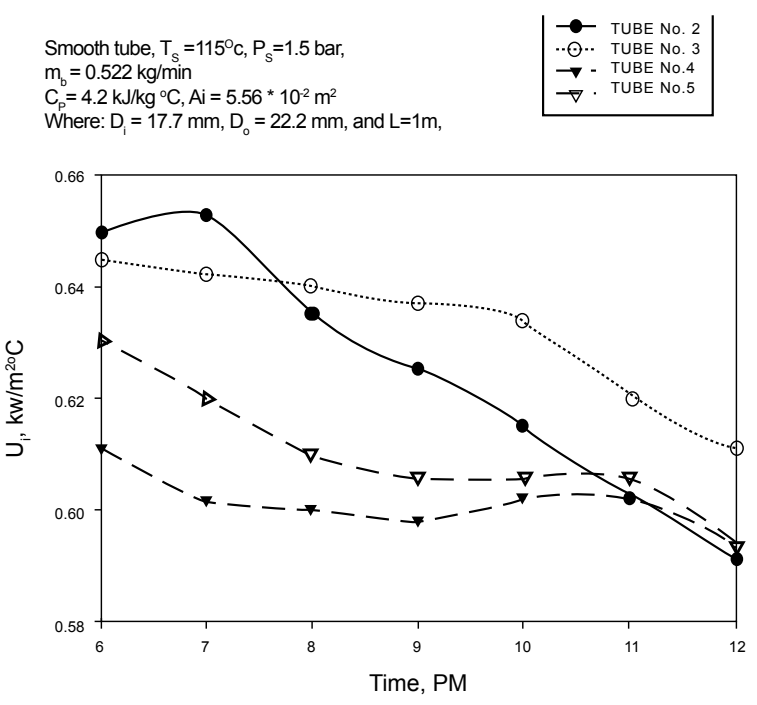

Figure 3: Overall Heat Transfer Coefficient for Brine Water vs. Time.

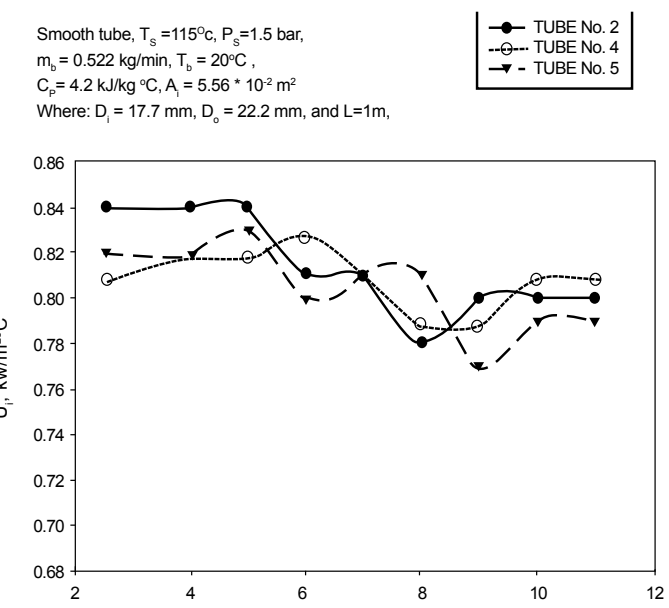

Figure 4: Overall Heat Transfer Coefficient for Potable water vs. Time.

\section{Sources of errors}

Certainty Errors with sources given as:

a) Flow-meters:

- Reading a flow scale graduation is a source of error.

- Flow meters are fitted up-stream of the tested tubes. This could cause unfilled tube with coolant, producing an error in measurements and a vibrated locator line on scale graduation for the considered flowmeter.

b) Flow temperature, range and thermocouples:

- Disregarded variation for any of the precedent given parameters will accumulate to the deficiency of the measured coolant outlet flow temperature.

- In the comparative analysis; fresh water in a smooth tube vs. brine water in a like tube, where same temperature range is preferable in application, to avoid deficient results.

- Thermocouple's direction of insertion would be a source of error. Example: Insertion in a perpendicular position to the direction of the

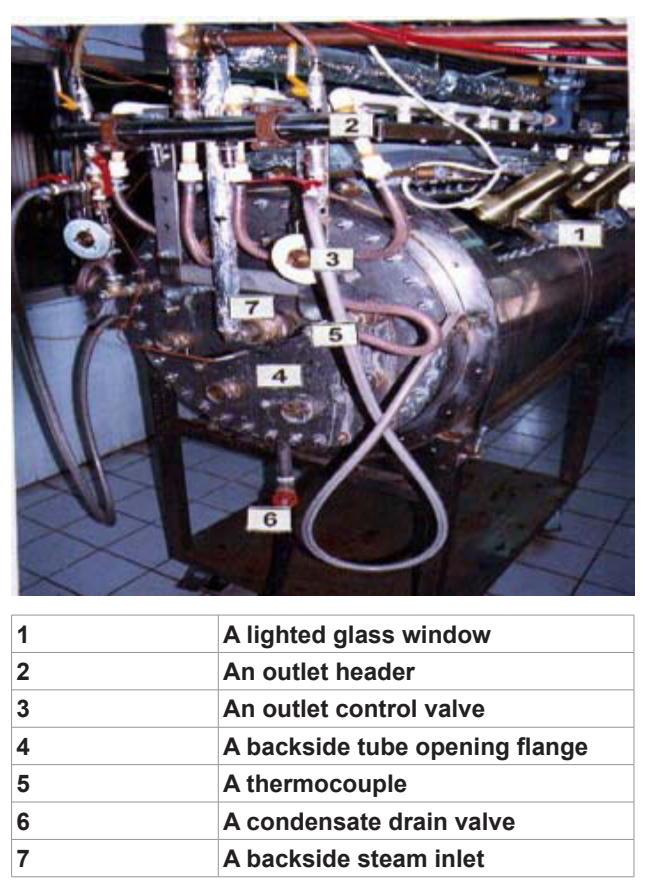

Figure 5: An Overall Back View of Test Rig (B) [12]

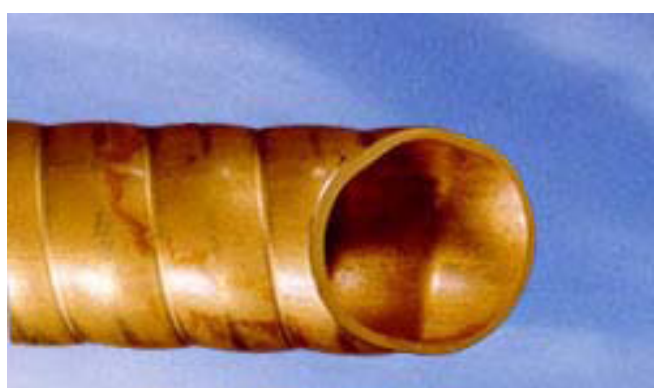

Figure 6: Used Enhanced Tube [12]. 
Citation: Kalendar A, Galal T, Al-Saftawi A, Zedan M, Karar SS, et al. (2012) Heat Transfer Characterization of Enhanced Condenser Tubes; Comparison with Conventional Type, Utilizing a Developed Design for Test Apparatus. J Appl Mech Eng 1:105. doi:10.4172/21689873.1000105

Page 4 of 8

fluid flow will develop vortices around the tip and consequently producing a bubbled flow.

c) Inlet Temperature variation:

- Diversity of coolant inlet temperature is thoroughly due to:

- Wide variation of the seasonable ambient temperature.

- Employing a closed cycle of cooling water.

d) Back pressure to the flow:

The vertical assigned level of the down- stream header played role with the existing accuracy of data results. The downstream header is to be raised up vertically, in relative to the up-stream one, until certainty that the tubes are filled fully with coolant.

\section{e) Steam distribution:}

Steam is introduced into test-rig through a single port on top of the upper-side of the condenser. The design provides unsymmetrical distribution of steam through-out the chamber.

\section{f) Ventilation:}

Coolant outlet temperature is significantly higher. Bubbles existence and appearance are due to entrainment of air into circulating cooling system and bubbles accumulated inside the tested tubes. Bubbled flow altered the measurement characteristics of the main stream, since it gives:

\section{- Misleading temperature \\ - Misleading flow rate \\ g) Creation of two phase flow:}

The problem of creating such flow is a result of using temperature application, leads the fluid to boiling point.

h) Steady-state duration time period and how to be minimized.

I) Mutual heat transfer interaction.
J) Boiler and used circulating pump:

-Used type of boiler is the source of errors in measurement, where many problems are countered during its service.

- Used type of pump, if not suitable for fouled water. Accordingly, clogging is happened frequently when brine water took-place in circulation.

The cubic box of test rig (A), simulating the steam condenser has to be redesigned. Since, buckling as well as cracks developed in the plixcyglass (12 $\mathrm{mm}$ thickness) box's wall due to the thermal stresses.

\section{Experimental Observations on Test-rig (B)}

An overall front view of test rig is shown in figure 5 with the type of used tube is given in figure 6. The condenser consists of a drum, cooling tubes evenly spaced in the drum and steam distribution pipe. Location of simultaneous tested tubes; corrugated and smooth, are in dicated on a given schematic drawing of figure 7 , where use is made of two horizontally mounted tubes through which the coolant solution are flowing. The design is capable for testing eight cooling tubes at a time to unify the tested conditions. They distributed on an equal circular pitch angle. This symmetrical distribution provides primary means for a uniform coolant temperature distribution. The rig frame is designed using stainless steel 316 in two shells; outer and inner, thickness $2 \mathrm{~mm}$, with providing a thermal insulation in between, for the purpose of minimizing heat dissipation. Four windows built in the upper half of the considered shelled frame, with a heat resistance glass to help in watching the development inside the condenser during the experimental activity. A steam distribution pipe is located at the centre of the drum, contains holes in its entire surface to distribute the vapour evenly along cooling tubes. Coolant flow rate is measured by using a formed glass tube-type flow meter. Flow rates are determined by reading the scale graduation at centre of the float. Temperatures are to be taken by inserted thermocouples onto important points, where each thermo-couple is calibrated
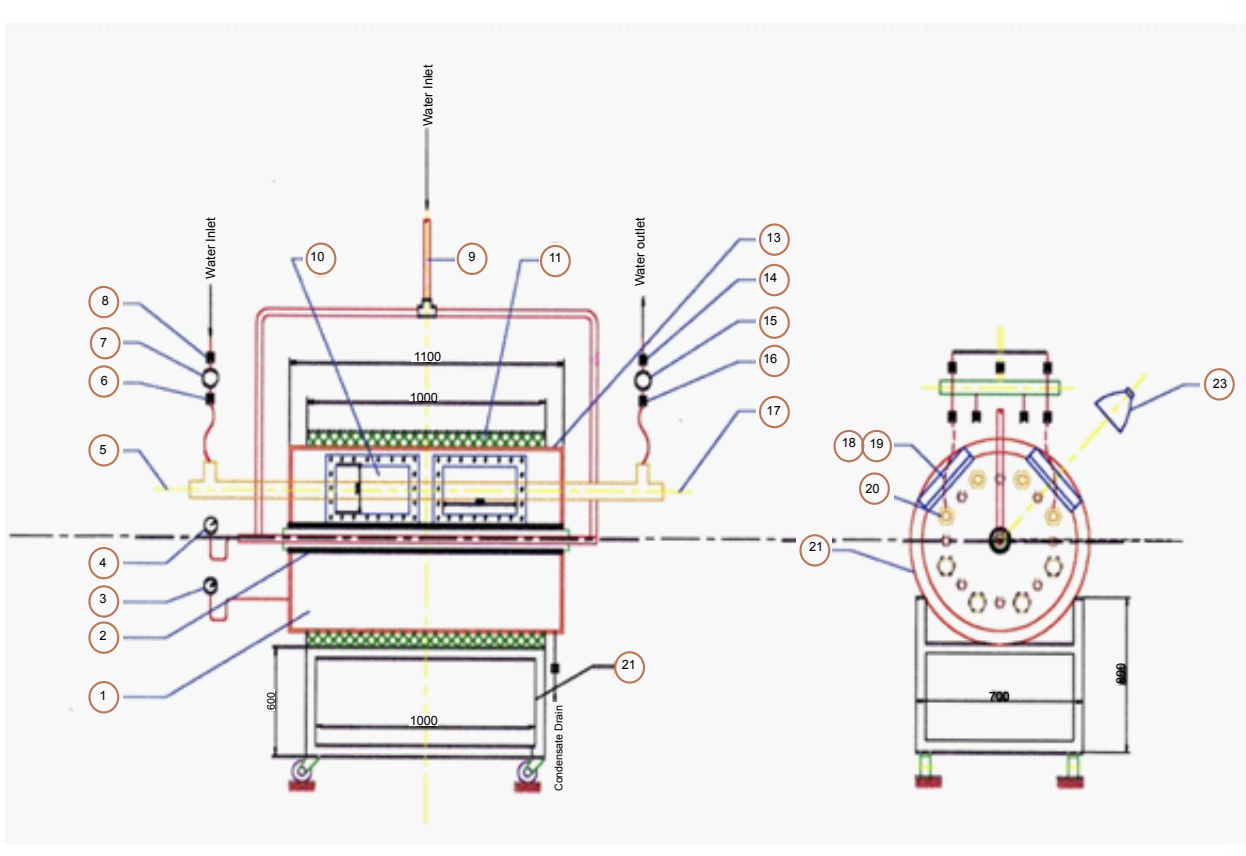

\begin{tabular}{||c|l||}
\hline 1. & TestDrum \\
\hline 2 & SteamDistribution Tube \\
\hline 3 & DrumPressureGauge (Test Drum) \\
\hline 4 & Steam Drum Inlet pressure gauge \\
\hline 5 & Water Inlet Thermocouple \\
\hline 6 & Inlet tube Control valve(2) \\
\hline 7 & Inlet Header \\
\hline 8 & Main Inlet Header Valve \\
\hline 9 & Steam Inlet Valve \\
\hline 10 & Sight Glass Windows(4) \\
\hline 11 & Insulation \\
\hline 12 & Lower Test Drum Thermocouple \\
\hline 13 & Inner Shell \\
\hline 14 & Main outlet Header Valve \\
\hline 15 & Outler Header \\
\hline 16 & Steam Inlet Thermocouple \\
17 & Water Outlet Thermocouple \\
\hline 18 & Upper Test Drum Thermocouple \\
\hline 19 & Opening for Testing Tubes (8) \\
\hline 20 & Testing Tubes (Corrugated) \\
\hline 21 & Outlet Shell \\
\hline 21 & Stainless Steel Frame \\
\hline 23 & Lamps (4) \\
\hline 24 & Testing Tubes (Smooth) \\
\hline 25 & Condensate Drain Valve \\
\hline 26 & Inlet Venting Valve (3) \\
\hline 27 & Outlet Venting Valve (3) \\
\hline & \\
\hline
\end{tabular}

Figure 7: Schematic Drawing of Test Rig(B) [12] 
Citation: Kalendar A, Galal T, Al-Saftawi A, Zedan M, Karar SS, et al. (2012) Heat Transfer Characterization of Enhanced Condenser Tubes; Comparison with Conventional Type, Utilizing a Developed Design for Test Apparatus. J Appl Mech Eng 1:105. doi:10.4172/21689873.1000105

Page 5 of 8

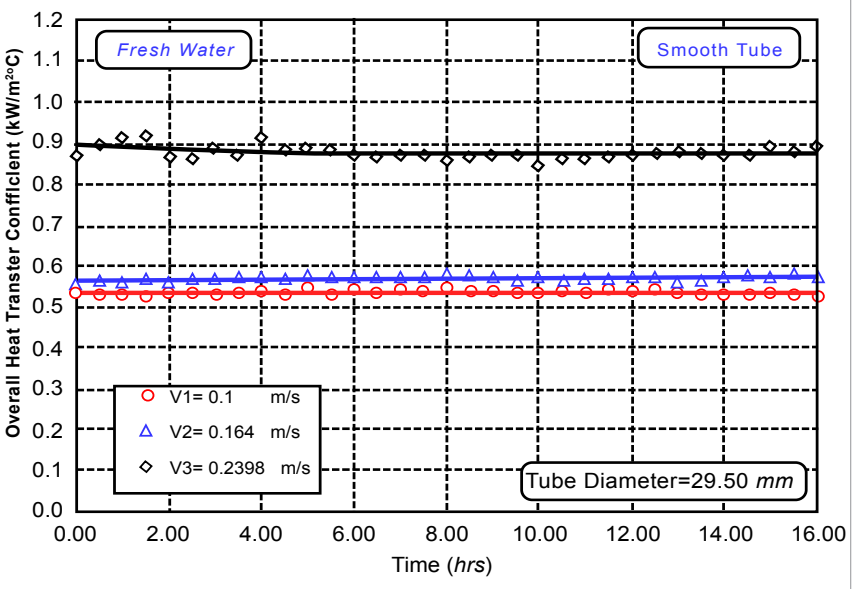

Figure 8: $U$ versus time for time, with fresh water For various used flow speeds \& D $=29.50 \mathrm{~mm}$

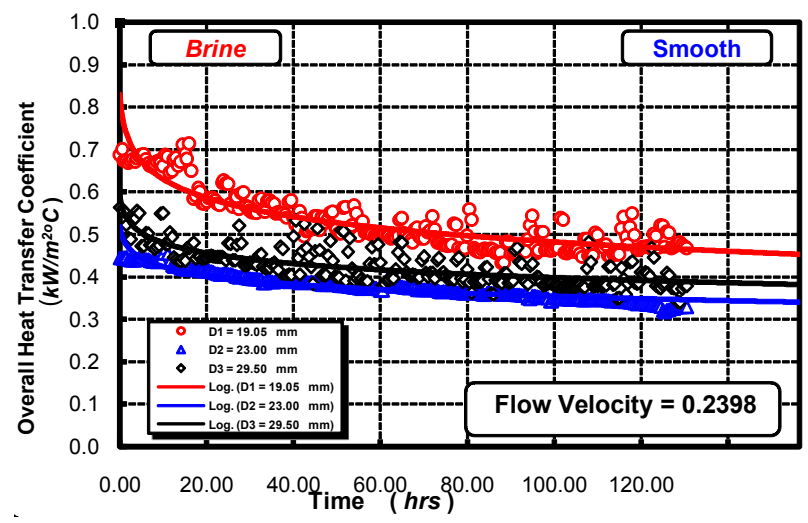

Figure 9 : Variation of the overall heat transfer coefficient $(U)$, with time for smooth tube when Brine water is used, for the three tube Diameters, and flow velocity $0.2398 \mathrm{~m} / \mathrm{s}$.

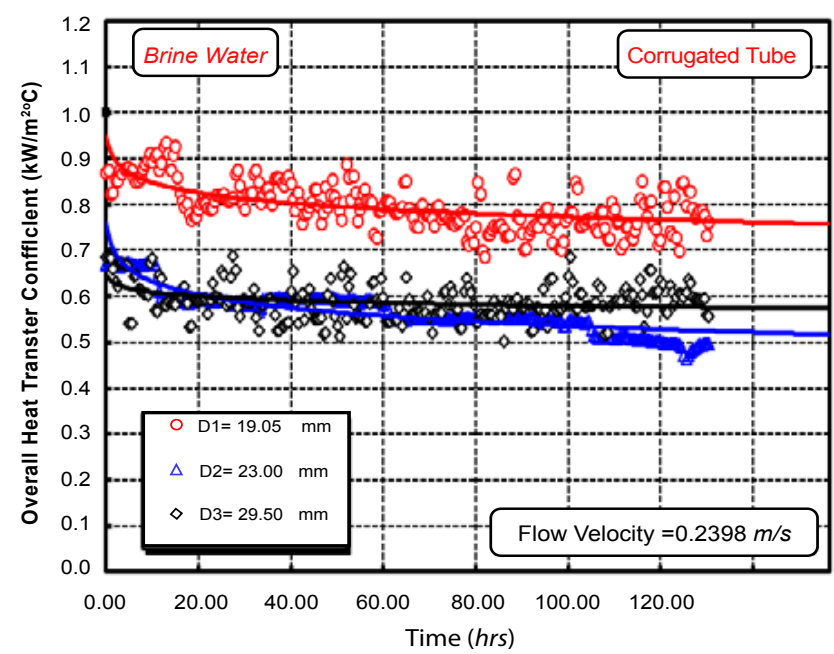

Figure 10: Variation of the overall heat transfer coefficient $(U)$, with time for corrugated tube with Brine water, on different tube diameters, and flow velocity $0.2398 \mathrm{~m} / \mathrm{s}$ and connected to a channel in the computer data card. Eight channels are used in our case; four inside the condenser, one for boiler outlet, one for coolant tube inlet, one for each coolant tube outlet, with outlet temperature is expected to be less than $100^{\circ} \mathrm{C}$. The test rig with its auxiliary components is simulating actual environmental real life of one stage heat exchange process in MSF desalination. The control system consists of a controller, a measurement and control link units. The controller and measurement units work together via control link units. Software is prepared to form a flexible data measurement and control system for up to 100 input channels. A provided software developed package allows user to write his algorithm to optimize system to a particular application. The inside dimensions of the cylindrical box are: $d$ internal $=78 \mathrm{~cm}, L_{\text {int }}=110 \mathrm{~cm}$. Steam is introduced to the condenser inthrough two central entrances. The steam distributor tubing inside the condenser consists mainly of two overlapped tubes. The inner steam tube is designed to scatter the steam whereas the outer one is built-in for the purpose of avoiding a creation of steam jet, with distributing the steam uniformly though out the condenser. For measuring the steam temperature inside the cylindrical condenser, four thermo-couples are built-in the rig; two on the upper half and two on the lower half. Through this arrangement, it has been proved that the steam temperature is distributed uniformly equally throughout the rig " $T_{\text {srig }}$ ". The temperature is taken almost constant throughout the experiments. Where, $T_{\text {srig }}$ being adapted by controlling the steam supply valves. Appendix(A) gives the experimental data recorded on the latest 10 hours of a certain test. Used thermocouples are chosen to be capable of standing for corrosive Medias, with covering the required range of measured temperatures. Different tube diameters are considered for trial; 19.05, 23 or 29.5 $\mathrm{mm}$. A data collection system is used in conjunction with this test rig. Flow-meters are fitted downstream of tested tubes rather than upstream to avoid previous cited problems. Bleeding valves are added throughout the water circulation loop. A three different coolant flow velocity of 0.1 , 0.1645 and $0.2398 \mathrm{~m} / \mathrm{s}$ are examined. The study is carried-out for two different coolants, fresh and brine water. Results are provided in the form of: overall heat transfer coefficient with fresh and brine water vs. time for both tubes on different flow speeds, overall heat transfer coefficient with brine water vs. time for both tubes on a critical coolant flow speed with various chosen tube diameters, asymptotic values of overall heat transfer coefficient with fresh water vs. tube diameters for both corrugated and smooth on a critical flow speed, asymptotic values of overall heat transfer coefficient with brine water vs. coolant flow speeds for both corrugated and smooth on a chosen critical tube diameter and the tube fouling resistance vs. time, using a tube diameter $23 \mathrm{~mm}$ and coolant flow velocity $0.1 \mathrm{~m} / \mathrm{s}$.

Justifications for the design of a novel model (B) of test-rig when compared with previous literature studies:

- The continuous experimental running hours used by this designed test-rig is $160 \mathrm{hrs}$.

- The cylindrical box simulated the steam condenser of test-rig, is designed with following modifications: a new configuration of steam distribution across the condenser is introduced, owning to the symmetrical distribution and the type of used diffuser. Resist buckling, as well as cracks due to the thermal stresses. Regards is given enough to eliminate mutual heat transfer effect between tubes. Since requirements are to dismantle the effect of any inferior external heat would exposed on each tube.

- The design is to help-in reaching the quasi-equilibrium state in a shorter period of time. 
Citation: Kalendar A, Galal T, Al-Saftawi A, Zedan M, Karar SS, et al. (2012) Heat Transfer Characterization of Enhanced Condenser Tubes; Comparison with Conventional Type, Utilizing a Developed Design for Test Apparatus. J Appl Mech Eng 1:105. doi:10.4172/21689873.1000105

Page 6 of 8

- A creation of two-phase flow, with this design is much more avoided.

- The applied flow speeds have been increased dramatically owing to the adjustable simulation of the actual circumstances in real desalination platform. Flow speed in current experiment is chosen to simulate the actual flow process. In actual platform system, the condenser tube long is $17.7 \mathrm{~m}$, with the associated flow speed is $2 \mathrm{~m} / \mathrm{sec}$. In this rig, the pipe long is taken $1.10 \mathrm{~m}$ with associated flow speeds are chosen as $0.1,0.1645$ and 0.2398 $\mathrm{m} / \mathrm{sec}$ respectively.

- Used corrugated tube is of Wolverine Tube Inc.

- Two sorts of flow meters are used: a classical glass flow-tube and a vortex type to fit the necessity of increased flow speed accuracy.

- A higher discharge capability pump is installed, to overcome the new set of selected range of flow velocities, in addition to reduced the problem of over-heating, by introduced an additional pump on stand-by position, while minimized the running time of each. Developed an automatic switching "on \& off "electric circuit to operate both pumps, with the capability of diminishing elapsed interval time.

- A more sophisticated boiler than the former is considered for use. Steam condition is adjusted a little superheated with temperature $<101^{\circ} \mathrm{C}$ to on atmospheric pressure to reach the rig in saturated condition.

- Bleeding valves is being arranged in several consequence locations up-stream of the tested tubes.

- The flow meters are fitted on down-stream of the tested tubes, rather than up-stream to avoid previous cited problems.

\section{Procedures}

In present work, tube material is aluminium-brass; with inside diameters 19.05, 23 and $29.5 \mathrm{~mm}$. Both smooth and corrugated with same diameter are mounted onto the rig, tested simultaneously with same coolant speed. To obtain required flow speeds on each, control valve mounted on the inlet-side of each tube are adjusted sequentially. Upon which, our model investigates three different flow speeds: $0.1,0.1645$ and $0.2398 \mathrm{~m} / \mathrm{s}$, in relevant to a tube length of $1100 \mathrm{~mm}$

\section{Overall heat transfer coefficient \& fouling resistance with re- sults}

Use is made of fresh water first on smooth tube, to gain experience with the heat performance of enhanced versus smooth tube. Experiment runs until achieving a constant value attained at steady state operation "asymptotic value" after 16 hours. While it takes from 140-160 hours when brine water is used. On speedT0.1, 0.1645 and $0.2398 \mathrm{~m} / \mathrm{s}$, figure 8 highlighted the data for smooth tube with diameter $29.5 \mathrm{~mm}$. The figure shows a slim difference in variation for the overall heat transfer coefficient $U$ between both speeds 0.1 and 0.1645 versus time, while speed $0.2398 \mathrm{~m} / \mathrm{s}$ has the most effective values over the time. When brine water is used on smooth tube figure 9 represents the variations of the overall heat transfer coefficient for various types of tube diameters 19.05, 23 and $29.5 \mathrm{~mm}$, with the most effective flow speed achieved from previous experiment $0.2398 \mathrm{~m} / \mathrm{s}$. Figure 10 shows the variation of corrugated tube's overall heat transfer coefficient when brine water is used, with significant higher value for tube diameter 19.05 over others. Consequently, asymptotic value of the overall heat transfer coefficient
$U^{\star}$ at different tube diameters $19.05,23$ and $29.5 \mathrm{~mm}$ is plotted on figure 11 for both smooth and corrugated tubes, with significant higher

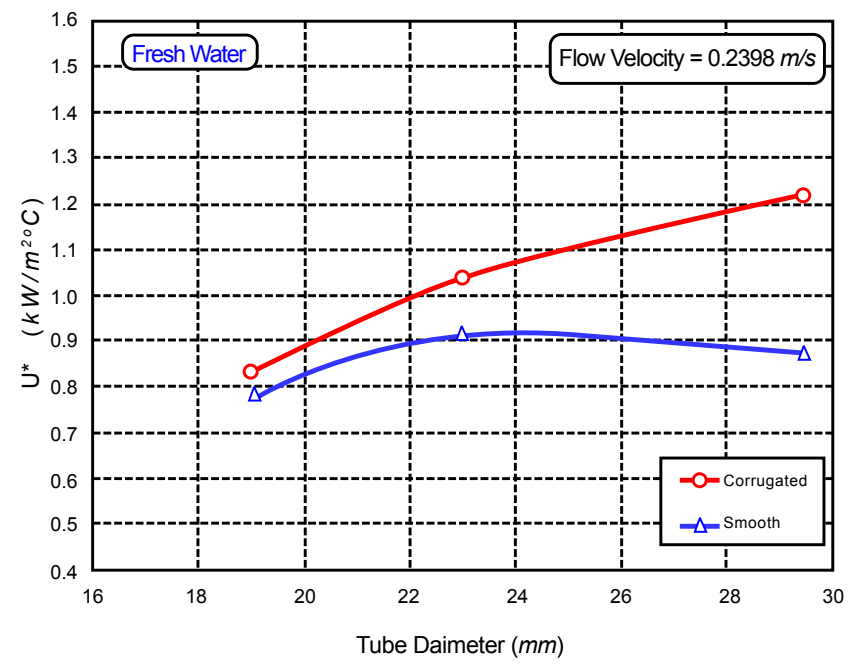

Figure 11: Comparison between corrugated and smooth of Asymptotic $U^{*}$ for Fresh water versus Tube Dia., With $V=0.2398 \mathrm{~m} / \mathrm{s}$.

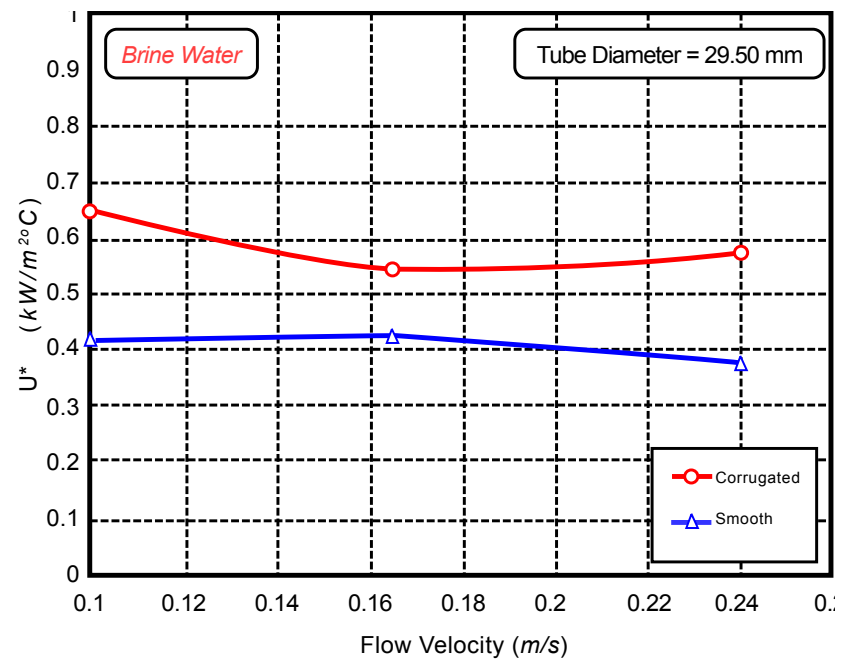

Figure 12: Comparison for Asymptotic $U^{*}$ for Brine water Versus Flow speeds with tube diameter $=29.50 \mathrm{~mm}$, between Corrugated and smooth tube.

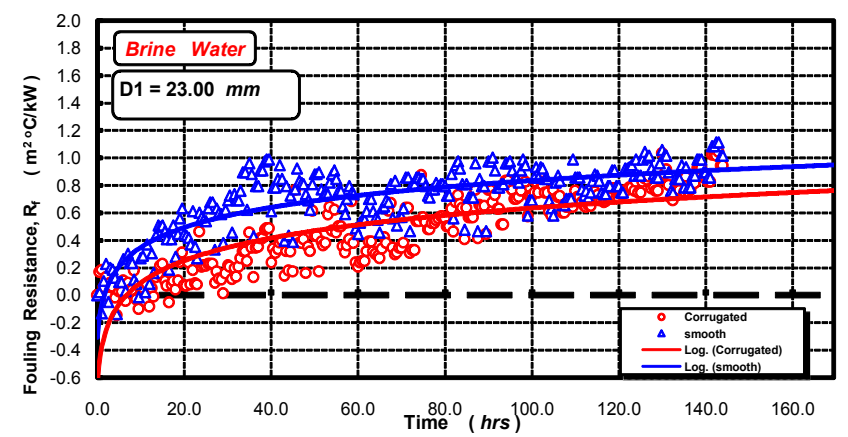

Figure 13: Fouling resistance $R_{f}$ for both tubes versus time, With $D=23 \mathrm{~mm}$ $\& V=0.1 \mathrm{~m} / \mathrm{s}$ 
Citation: Kalendar A, Galal T, Al-Saftawi A, Zedan M, Karar SS, et al. (2012) Heat Transfer Characterization of Enhanced Condenser Tubes; Comparison with Conventional Type, Utilizing a Developed Design for Test Apparatus. J Appl Mech Eng 1:105. doi:10.4172/21689873.1000105

value of $U^{\star}$ for $29.5 \mathrm{~mm}$ diameter over the others on flow speed 0.2398 $\mathrm{m} / \mathrm{s}$. While figure 12 shows asymptotic value of the overall heat transfer coefficient $U^{*}$ plotted versus used flow speeds for smooth and corrugated tube, with no significant change in $U^{\star}$ while increasing coolant flow speed from $0.1 \mathrm{~m} / \mathrm{s}$ to $0.1645 \mathrm{~m} / \mathrm{s}$ and $0.2398 \mathrm{~m} / \mathrm{s}$ respectively.

Fouling resistance is typically performed by measuring the total thermal resistance (1/UAi) for clean and fouled cases, Webb [1], with using the following formula [22]:

$$
R_{f}=\frac{1}{(U)_{f}}-\frac{1}{(U)_{c l}} \quad m^{20} \mathrm{C} / k W
$$

Where, subscript $f$ and $c l$ refer to fouled and clean conditions. Results for fouling resistance $(R f)$ for both corrugated and smooth tubes are illustrated on figure 13. As shown, fouling thermal resistance for both tubes increases with time, then attains about a constant asymptotic value after $140 \mathrm{hr}$. The figure also shows to how far the performance of corrugated tube is superior to its similar of smooth.

Comparing graphs, it is realized the effect of fouling on lowering the values of $U$ versus time by much. Through above given graphs and generated data, this study is significant to provide a useful correlation. As the tube diameter increases with increases flow speed, expectations are to achieve higher values for the overall heat transfer coefficient $U^{*}$. Corrugated tube performance has a less asymptotic fouling resistance when compared with its similar type of smooth tube.

\section{Conclusions}

Better performance reported for corrugated tube would reduces heat exchanger size, reduces coolant hold up volume, reduces the system design process time, reduces fouling potential and increases cleaning potential consequently to replace Ball Cleaning System. The actual circumstances in a real desalination plant-form are simulated with regarding the constituents: coolant flow speed, tube diameter and the type of employed liquid coolant. Tested corrugated and smooth tube at a time is to unify tested conditions on both. Other major parameters influenced the test circumstances are: inlet coolant temperature, inside temperature for the test-rig, inexistence of non-condensable gases and brine water concentration in ppm. Revealed study presents the influence of flow speeds on fouling pattern and the effect of tube diameter on its behaviour. Experimental results are discussed for both smooth and corrugated tube, when applying fresh and real brine water on different tube diameters 19.05, 23 and 29.5, with flow speeds $0.1,0.1645$ and $0.2398 \mathrm{~m} / \mathrm{s}$. In comparing data results, it is realized the effect of fouling on lowering the values of $U$ versus time by much. Corrugated tube performance has a less asymptotic fouling resistance when compared with its similar type of smooth tube. Through given presentation and generated data, interpretation is to show this study is significant to provide a useful correlation for future research. As the tube diameter increases, with increases flow speed, expectations are to achieve higher values of the asymptotic overall heat transfer coefficient.

\section{Acknowledgement}

This work has been financially supported by PAAET; project no. TS-08-11

\section{Nomenclature}

$T_{b i}$ Brine temperature at the entrance to the condenser, ${ }^{\circ} \mathrm{C}$

$T_{b o, c}$ Brine temperature at the exit from the condenser, ${ }^{\circ} \mathrm{C}$

$d T_{b o}{ }_{c}$ Temperature difference for the corrugated tube, equal to $\left(T_{b o, c-T b}\right),{ }^{\circ} \mathrm{C}$

$d T_{b o, s}$ Temperature difference for the corrugated tube, equal to $\left(T_{b o, s-T b}\right),{ }^{\circ} \mathrm{C}$
$T_{\text {s,rig }}$ Steam temperature inside the test rig ${ }^{\circ} \mathrm{C}$

$T_{s, b o i l}$ Steam temperature out of boiler, ${ }^{\circ} \mathrm{C}$

\section{References}

1. Webb R L (1994) Principles of Enhanced Heat Transfer, John Wiley \& Sons Inc, New York.

2. Han JC, Glicksman LR, Rohsenow WM (1978) An Investigation of Heat Transfer and Friction for Rib-Roughened Surfaces, Int J Heat Mass Transf 21: 143-1156.

3. Webb RL (1979) Toward a Common Understanding of the Performance and Selection of Roughness for Forced Convection. Studies in Heat Transfer: A Festschrift for E.R.G. Eckert, J.P. Hartnett et al., Edn, Hemisphere Publishing Corp, Washington: 257-272.

4. Fenner GW, Ragi EG (1979) Enhanced Tube Inner Surface Heat Transfer Device and Method, USA.

5. Gee DL, Webb RL (1980) Forced Convection Heat Transfer in Helically RibRoughened Tubes. Int J Heat Mass Transf 23: 1127-1136.

6. Nakayama W, Takahashi K, Daikoku T (1983) Spiral Ribbing to Enhance SinglePhase Heat Transfer inside Tubes. Proceeding of the ASME-JSME Therma Engineering Joint Conference, Honolulu, HI, ASME, New York, 503-510.

7. Sumitomo (1983) Technical Data of Tred-Fin, Sumitomo Light Metal Industries, Aichi, Japan.

8. Bergles AE (1985) Techniques to Augment Heat Transfer- second- Generation Heat Transfer Technology. J Heat Transfer 110: 1082-1096.

9. Sethumadhavan R, Rao MR (1986) Turbulent Flow Friction and Heat Transfer Characteristics of Single-and Multi-Start Spirally Enhanced Tubes. J Heat Transfer 108: 55-61.

10. Raja Rao M (1988) Heat Transfer and Friction Correlations for Turbulent Flow of Water and Viscous Non-Newtonian Fluids in Single -Start Spirally Corrugated Tubes. Proceedings of the National Heat Transfer Conference, HTD-96, Vol. 1 , ASME, New York, 677-683

11. Takahashi K, Nakayama W, Kuwahara H (1988) Enhancement of Forced Convection Heat Transfer in Tubes Having Three-Dimensional Ribs," Heat Transfer Japanese Research 17: 12-28.

12. Watkinson AP (1990) Fouling of Augmented Heat Transfer Tubes. Hea Transfer Engineering 11: 57-65.

13. Cuangya L, Chuanyun G, Chaosu W, Jinshu H, Cun J (1991) Experimenta Investigation of Transitional Flow Heat Transfer of Three-Dimensional Internally Finned Tubes. Advances in Heat Transfer Augmentation and Mixed Convection M.A. Ebadain, D.W. Pepper, and T. Diller, Eds., ASME Symposium, Vol. HTD Vol. 169, ASME, New York, 45-48.

14. Kim N-H, Webb RL (1991) Particulate Fouling of Water in Tubes Having Two Dimensional Roughness Geometry. Int J Heat Mass Transfer 34: 2727-2738.

15. Chamra LM, Webb RL (1994) Modelling Liquid-Side Particulate Fouling in Enhanced Tubes. Int J Heat Mass Transfer 37: 571-579.

16. Bergles AE, Somerscales EFC (1995) The Effect of Fouling on Enhanced Hea Transfer Equipment. J Enhanced Heat Transfer 2: 157-166.

17. Rudy TM (1982) A Theoretical and Experimental Study of Condensation on Single, Integral-fin Tubes. PhD Dissertation, Pennsylvania State University.

18. Chamra, LM (1992) A Theoretical and experimental study of particulate fouling in enhanced tubes. PhD thesis, The Penn State University.

19. Wei Li (1998) A theoretical and experimental study of fouling in enhanced tubes in cooling tower systems. PhD thesis, The Penn State University.

20. Ahmad Kalendar (1998) Enhanced Condenser Tubing versus Energy Saving, Proceeding of the International Conference on Energy Research and Development, Vol. II (Kuwait) 603-619.

21. Kalendar AY, Griffiths AJ (2001) Performance Study of Enhanced and Smooth Surface Tubes in a System Condenser of a Multi-Stage Flash Desalination Unit, Desalination, Elsevier 134: 269-283.

22. Galal T, Kalendar A, Al-Saftawi A, Zedan M, (2007) Condensate Water Quantity Function of Condenser Tubing Type for Innovation MSF System, ADST 
Citation: Kalendar A, Galal T, Al-Saftawi A, Zedan M, Karar SS, et al. (2012) Heat Transfer Characterization of Enhanced Condenser Tubes; Comparison with Conventional Type, Utilizing a Developed Design for Test Apparatus. J Appl Mech Eng 1:105. doi:10.4172/21689873.1000105

Page 8 of 8

Proceedings, International Conference Desalination Technologies and Water Reuse, Sharm El-Sheikh, May 7-8.

23. Kalendar, A. Al-Saftawi, Galal T (2007) "Comparative Thermal Performance Analysis of Enhanced Condenser Tubing Type for Innovation MSF System",
ADST Proceedings, International Conference Desalination Technologies and Water Reuse, Sharm El-Sheikh, May 7-8.

24. Galal T, Kalendar A, Al-Saftawi A, Zedan A (2010) Heat transfer performance of condenser tubes in an MSF desalination system, Journal of Mechanical Science and Technology 24: 2347-2355. 